\title{
Human Capital, Growth, and Inequality in Russia ${ }^{1}$
}

\author{
Chengze Simon Fan \\ Lingnan University, Tuen Mun, N.T., Hong Kong, People's Republic of China
}

Jody Overland

University of Colorado, Denver, Denver, Colorado 88217

and

\begin{abstract}
Michael Spagat
Royal Holloway College, University of London, Egham, Surrey TW20 OEX, United Kingdom
\end{abstract}

Received October 19, 1998; revised August 16, 1999

\begin{abstract}
Fan, Chengze Simon, Overland, Jody, and Spagat, Michael—Human Capital, Growth, and Inequality in Russia
\end{abstract}

Our model captures the fact that Russia has both much human capital and an education system that produces the wrong skills for a market economy. We define a rule for the timing of educational restructuring that is Pareto optimal and that dominates all later times in a Paretian sense while simultaneously reducing inequality. We demonstrate that failure to implement restructuring early in the transition process is likely to produce a very long delay that will significantly reduce Russia's human capital. A retreat from subsidizing public education is likely to be counterproductive. We argue that early educational restructuring should be emphasized in Russia's transition strategy. J. Comp. Econ., December 1999, 27(4), pp. 618-643. Lingnan University, Tuen Mun, N.T., Hong Kong,

${ }^{1}$ This research was generously supported by the National Council on Soviet and East European Research and IREX. We thank two anonymous referees, Graziella Bertocchi, George Bindon, Joe Brada, John Bonin, Rachel Friedberg, Oded Galor, Stephen Heyneman, Yaakov Khazanov, Peter Murrell, Arlene Overland, Gil Skillman, Judy Thornton, Dani Tsiddon, David Weil, and seminar participants at Brown University, Wesleyan University, Bellcore, the University of Virginia, the University of Illinois, Indiana University, the University of Washington, the University of Pittsburgh, the Central Economics and Mathematics Institute in Moscow, the Tilburg University, Universitá di Modena, the World Bank, the ASSA meetings in Boston, the Conference on Economies in Transition in Falls Church, Virginia, the Boston meetings of the Eastern Economic Association, and the Society for Economic Dynamics and Control meetings in Mexico City. 
People's Republic of China; University of Colorado, Denver, Denver, Colorado 88217; and Royal Holloway College, University of London, Egham, Surrey TW20 OEX, United Kingdom. () 1999 Academic Press

Key Words: human capital; growth; inequality; Russia; comparative dynamics.

Journal of Economic Literature Classification Numbers: D9, H4, I2, O4, P5.

\section{INTRODUCTION}

Much recent theoretical literature has stressed the importance of human capital for economic growth, e.g., Lucas (1988), Azariadis and Drazen (1990), and Lucas (1993). Significant empirical evidence in support of this relationship exists, e.g., Barro (1992), Katz (1992), and Mankiw et al. (1992). A casual reading of this research suggests that Russia's grand intellectual traditions, combined with widespread literacy, numeracy, and technical training should provide a powerful basis for prosperity in both the short-run and the long-run. ${ }^{2}$ Nevertheless, Russia presently combines West European human capital levels with the living standards of a middle income developing country. ${ }^{3}$ Moreover, Russia has experienced sharply negative growth rates for more than a decade. We argue that the final resolution of this puzzle may be that Russia's human capital stock will decline to match its standard of living rather than the opposite, that Russia's standard of living will rise to meet its human capital stock.

Incentives for Russian young people to acquire human capital are poor for two main reasons. First, the Russian educational system, to a first approximation just a deteriorating version of the Soviet system, does not currently serve as an efficient tool for market-oriented human capital investments. Rather, it is still geared toward teaching the skills demanded by the Soviet economy. ${ }^{4}$ Second, Mincerian returns to the human capital that is obtainable within the Russian system are not particularly high. Aage (1996) finds only a very weak link between earnings and education in 1992. Brainerd (1998) argues that the returns to education increased significantly between 1991 and 1994, but Nesterova and Sabirianova (1998) found a strong reversal from 1994 to 1996. Ogloblin (1997)

\footnotetext{
${ }^{2}$ For evidence that Russia's human capital stock is very high, see Balzer (1993), OECD (1994), and World Bank (1995). Graham (1993) provides a lucid general survey of Soviet and Russian science. Note that Russia has by far the world's highest concentration of scientists and engineers (Boesman, 1993).

${ }^{3}$ Secondary and tertiary enrollment percentages are 55 and 18 , respectively, for middle-income countries (MI), 90 and 25, respectively, for Russia, and 93 and 36, respectively, for high-income countries (HI). Primary pupil/teacher ratios are 25 for MI countries, 9 for Russia, and 17 for HI countries. However, per capita GDP is $\$ 2,490$ for MI countries, $\$ 2,510$ for Russia, and $\$ 22,160$ for HI countries. For sources see World Bank $(1992,1994)$ and the UN Demographic Yearbook (1993).

${ }^{4}$ The World Bank (1995) criticizes the Russian education system for producing the wrong mix of specialties, i.e., primarily scientists and engineers to serve the Soviet military-industrial complex, for overemphasis on specialization, and for overreliance on rote learning. One need not accept all of these points in order to agree with our general point that the education system is not suited to the needs of a modern market economy.
} 
shows that returns to human capital were weak at the end of 1996. Moreover, the value of education almost certainly fell after the August 1998 market crash. Consequently, many young people are withdrawing, fully or partially, from school in order to work, for example, as taxi drivers, street traders, and Mafiosi. ${ }^{6}$

In any society, families play a crucial role in passing knowledge, skills, and the desire to learn from older to younger generations so that there is a dynastic, or local, intergenerational externality to human capital acquisition. Russia follows this pattern. ${ }^{7}$ Well-educated individuals are able to facilitate the human capital acquisition activities of their children more effectively than can parents who are poorly educated. Furthermore, the implementation of leading-edge technology and the development of the infrastructure required to sustain market activities depend heavily on human capital levels (Galor and Tsiddon, 1997; Barro and Sala-i-Martin, 1997). Thus, there is a global intergenerational productivity externality associated with individual human capital acquisition: a generation with high levels of human capital leaves a more productive economy in its wake than does one in which human capital levels have deteriorated. ${ }^{8}$

Consider the next two generations in Russia. Today's younger generation, the children, while blessed with well-educated parents, lacks the economic incentives to invest in human capital. If the children continue to follow the money, they will become significantly less educated than their parents, thereby placing

${ }^{5}$ Note that wages tell only part of the story. Intellectual work received much better non-monetary compensation than other work in the form of weekend dachas, priority access to cars, housing and other consumer goods, opportunities for vacations and foreign travel, higher social status, much safer work environments, and, for women, the possibility of marrying a less alcoholic and violent husband. If these considerations were included, one might find that returns to human capital have been lower throughout the Russian period than they were under communism.

${ }^{6}$ This internal brain drain phenomenon is very pronounced. In just the last three years, the proportion of young people in higher education has dropped by $10 \%$ while there is widespread agreement that class attendance and school performance at all levels have dropped dramatically. Moreover, children are deeply involved in crime; see Kitaev (1994) and Jones (1994).

${ }^{7}$ The ratio of the percentage of university students who were the offspring of professionals to the percentage who were the offspring of nonprofessionals was 2.1 in Russia in 1970, 2.4 in France in 1974, 2.4 in the UK in 1969, 1.8 in Japan in 1968, and 1.5 in the United States in 1954 according to Heyneman (1995). Sobkin and Pisarskii (1992, 1993a, 1993b), Lazarev et al. (1993) and Jones (1994) provide extensive evidence that both high and low education levels have a very strong tendency to be self-sustaining within families in Russia.

${ }^{8}$ Note that, in our model, it is crucial to distinguish between three distinct roles for human capital: (1) increasing wages for the individual who possesses human capital; (2) facilitating the acquisition of human capital by the offspring of the individual with human capital; (3) increasing the rate by which the Russian economy acquires and implements leading-edge technology. Much existing Russian human capital has very low market value; i.e., it performs poorly according to its first role. However, just because many adults cannot earn high wages based on the human capital that they accumulated through the Soviet education system does not mean that they are bad parents. For example, Russian physicists are currently paid extremely poorly, but their educations place them in excellent positions to produce offspring who will be well educated and well rewarded by the market. This intergenerational educational link lies at the heart of our analysis. 
their own children, the grandchildren, in a difficult bind for two separate reasons. First, the children's' failure to invest in human capital will retard the economy's productivity growth and, hence, wages. Second, as poorly educated parents, the children will be ineffective in facilitating the grandchildren's efforts to acquire human capital. Both factors will encourage many of the grandchildren to duplicate the children's decisions not to invest in themselves. Thus, delay in educational restructuring translates into a persistent drop in productivity, as the process of rebuilding Russia's intellectual level after its initial deterioration would be protracted and costly. This imposes great welfare costs on the subsequent generations that have lower human capital levels and less productivity than they would have had if restructuring had been carried out earlier.

On the other hand, early educational reform can reverse this deterioration scenario. Making the education system into an effective instrument for human capital investment would encourage many children to invest intensively in human capital, boosting productivity growth and creating more effective parents. The key mechanism underlying this result is that early restructuring preserves the intergenerational continuity of Russia's intellectual traditions, while these traditions adapt to the requirements of the market economy of the 21 st century.

A second conclusion is that if educational restructuring is not implemented very early in the transition process, it is likely to be delayed for a very long time. This is an important point because while most analysts would agree that education in Russia must ultimately be reformed, many believe that restructuring should receive low priority and be postponed in favor of other more pressing needs. In practice, the Russian government has followed this policy by doing little with human capital development other than slashing its funding. However, our results suggest that this policy is a mistake because the discrete loss of human capital precipitated by a failure to implement an early educational restructuring diminishes the impact of a late initiative. Once intergenerational intellectual continuity is broken, reform has only limited potential to reverse the damage.

A third result is that early restructuring reduces inequality by providing underprivileged youth with an avenue for upward mobility. Without early reform, a society tends to divide into two hardened classes, i.e., educated and uneducated. The offspring of uneducated parents remain trapped in poverty because the education system does not allow these children to overcome their disadvantaged backgrounds. This describes the current Russian reality: inequality has been rising dramatically as the rich retreat to a world of private schools and hospitals while the poor are left with a crumbling public system (World Bank, 1995).

A related point is that attempts to achieve full cost recovery for an educational restructuring too quickly are likely to be counterproductive. The real power of educational restructuring comes from its role in preserving intergenerational intellectual continuity. The trick is to induce the children of moderately educated parents to invest seriously in human capital, placing them in a strong position to 
contribute to their own children's education. If educational reform is largely financed through hefty tuition payments, these offspring of moderately educated parents might choose to forego significant human capital acquisition because it is rendered unprofitable. If so, intergenerational continuity would be lost in these families.

Finally, we wish to emphasize that it is precisely the presence of a significant human capital stock that leads to the conclusion that early educational reform should have a high-priority claim on society's resources. If there were only weak intellectual traditions, as is the case in typical middle-income developing countries, intergenerational continuity would not be an issue and it might be reasonable to postpone a major human capital initiative. While our paper is written primarily with Russia in mind, the analysis is applicable to of all the countries of the former Soviet Union and Eastern Europe or any transitional economy undergoing major structural change that dramatically reduces the rewards to its existing human capital stock.

Our work falls within the literature that deals with transition economics from a theoretical perspective. Surveys include Blanchard (1995) and Dewatripont and Roland (1996). The role of human capital is a neglected subject, but there are theoretical papers by Alexeev and Kaganovich (1996) and Spagat (1995). The former uses an adverse selection argument to explain why the returns to human capital have been so low during the transition period in Russia. The latter studies the role of political uncertainty in the deterioration of Russia's human capital stock. Our model shares some of the characteristics of models found in the literature on multiple steady states in that initial conditions play a role in the determination of equilibria (see Azariadis, 1993, pp. 444-452). It is also similar to two-factor models such as that of Mulligan and Sala-i-Martin (1993), in which an economy begins with an abundance of one factor relative to the other so that there is a tendency for the abundant factor to decline along the transition path.

The plan of the paper is as follows. In Section 2, we model the Russian economy, using a two-sector overlapping generations framework with a "learning-or-doing" technology, placing an emphasis on the importance of human capital. Section 3 contains our main results. There always exists a unique and stable steady-state level of human capital to which all skilled dynasties converge. The human capital of each dynasty can only follow three types of time paths, i.e., steady increase, steady decrease, or a U-shaped. We define a rule that determines when the society will choose to implement educational restructuring; this rule turns out to select a Pareto optimal restructuring time that Pareto dominates all later times and produces a more egalitarian society than would obtain under later educational restructuring. We show that if educational restructuring is not carried out very early in the transition process, then it is likely to be delayed for a very long time with the attendant loss of dynastic human capital continuity. We analyze alternative financing schemes that increase the feasibility of early restructuring. Section 4 concludes with some policy discussion. 


\section{THE MODEL}

\subsection{Production and Human Capital Acquisition}

The economy produces two types of goods using constant-returns-to-scale technologies. The first is produced in the traditional sector that uses unskilled labor as its single input. For simplicity, we take the production function to be

$$
X_{t}=L_{t},
$$

where $X_{t}$ is the output from and $L_{t}$ is the unskilled labor input into the traditional sector at time $t$, where $t=0,1,2, \ldots$ We normalize the value marginal product of labor in this sector to 1 .

The second sector, which we call modern, uses units of human capital in the form of efficiency units of skilled labor to produce output according to

$$
Z_{t}=A_{t} H_{t},
$$

where $Z_{t}$ is output and $H_{t}$ is the units of human capital input, at time $t$. $A_{t}$ represents the overall productivity in the modern sector. The relative world price for modern goods is $p$. In the modern sector, the wage rate per efficiency unit of human capital in period $t, w_{t}$, will be equal to its value marginal product; i.e.,

$$
w_{t}=p A_{t} .
$$

We do not allow parents to buy human capital directly for their offspring. Rather, parents pass down to their children the facility for human capital acquisition through family interaction. Higher parental human capital always enables parents to have enhanced effectiveness in teaching their children how to learn. Besides having intuitive appeal, there is strong empirical support for this parental effect in the case of Russia.

There are $N$ dynasties of agents indexed by $i$, each of whom lives for two periods. The adults at time $t$ are referred to as generation $t$. Every individual belongs to a family unit that contains a child and a parent. Each child is endowed with one unit of time that he allocates between unskilled work and the acquisition of human capital beyond the standard level attained by all members of the society. Every agent works for one unit of time as an adult.

Let $e_{i t} \in[0,1]$ denote the amount of time individual $i$ of generation $t$ devotes to the development of his skills and education as a child during period $t-1$, and let $h_{i t}$ stand for the level of human capital that he attains. There are two aspects of our formulation. First, the effectiveness of a child's effort in acquiring human capital depends positively on the level of human capital reached by the child's parent. This parental effect creates a local intergenerational externality since the child's welfare does not figure into the parent's decision to acquire human capital. Second, a higher quality education system enhances the effectiveness of children's human capital acquisition efforts. Specifically, 


$$
h_{i t}=\left(E_{t-1}+h_{i, t-1}\right)^{\alpha} e_{i t}^{1-\alpha},
$$

where $E_{t-1}>0$ and $0<\alpha<1$ are treated as fixed parameters by individual decision makers. ${ }^{9}$ Here, $E_{t-1}$, which is a governmental policy variable, represents the quality of the educational system available to generation $t$ in its childhood, i.e., in period $t-1$. Equation (4) supports the following interpretation when $E_{t-1}$ is fixed. Human capital is built up gradually over generations because even the extraordinary efforts of young people will yield only limited results unless they are reared in highly educated families. On the other hand, the failure of one child to take advantage of his educational opportunity might have repercussions for all future generations in his family by undermining their efforts to invest in themselves.

\subsection{Parental Human Capital and Optimal Career Choice}

We now model the optimal level of education and subsequent career choice of agents and its relationship to their parents' human capital. We show at the end of this section that a combination of low parental human capital, poor wages, and a weak education system can lead to a discrete intergenerational drop in human capital.

For simplicity, we assume that consumption is the only argument in agents' utility functions and that all agents can borrow and lend freely at the fixed interest rate $r$. Below we introduce a tax and transfer system with the property that income, after taxes and transfers, is strictly increasing in pre-tax income. We show, in Lemma 1, that individuals will allocate their time so as to maximize their pre-tax lifetime earnings. Moreover, we simplify further by requiring supply and demand to balance only in the aggregate, but not necessarily sector by sector. This could be supported either by a small open economy assumption or by considering the outputs of the two sectors as perfect substitutes. These simplifications allow us to consider only the pre-tax income maximization problem; i.e., any utility function with positive marginal utility of consumption will yield identical results.

As an adult, each agent possesses a quantity of skilled labor equal to his level of human capital. Adults may allocate their work effort between skilled and unskilled work. The pre-tax earnings for individual $i$ of generation $t$ in future value terms, $I_{i t}$, will be

$$
I_{i t}=\left(1-e_{i t}\right)(1+r)+w_{t} h_{i t}
$$

if he allocates $e_{i t}$ units of time to human capital acquisition as a child and then works fully in the modern sector as an adult. Pre-tax income will be

\footnotetext{
${ }^{9}$ This type of formulation was introduced in Lucas (1988) and Becker et al. (1990) and is now used widely.
} 


$$
I_{i t}=\left(1-e_{i t}\right)(1+r)+1
$$

for individual $i$ of generation $t$ if he allocates $e_{i t}$ units of time to human capital acquisition as a child but then works in the traditional sector as an adult. However, in equilibrium, no individual will waste time training to perform only unskilled work as an adult.

The full problem can be stated as follows. The choice variables for individual $i$ are $e_{i t}$, the amount of time spent on human capital acquisition as a child, and $l_{i t}$, the amount of time to be spent working in the modern sector as an adult. Individual $i$ of generation $t$ solves

$$
\max _{0 \leq e_{i t}, l_{i t} \leq 1}\left(1-e_{i t}\right)(1+r)+w_{t} h_{i t} l_{i t}+1-l_{i t}
$$

$$
\text { s.t. (4) and given } h_{i, t-1} \text { and } w_{t} \text {. }
$$

The problem is a simple two-stage dynamic program that can be solved by finding the optimal choice of $l_{i t}$ as a function of the possible conditions that can obtain when $i$ is an adult and then solving for $e_{i t}$ taking into account $i$ 's optimal behavior as an adult. We will assume that, in the knife-edge case where $i$ would earn the same money in both the skilled sector and the unskilled sector, he will choose to become skilled.

Note that if $i$, as a child, chooses to remain unskilled in the second period, i.e., he sets $e_{i t}$ and consequently $h_{i t}$ equal to zero, he will work exclusively in the traditional sector as an adult; i.e., he will set $l_{i t}$ equal to zero. Conversely, any adult who works only as an unskilled laborer will have invested nothing in human capital acquisition as a child. It is also clear that, except in the knife-edge case, any adult will work exclusively either in the modern sector or the traditional sector, depending on whether $w_{t} h_{t}$ is greater than or less than $2+r$. Therefore, when an individual chooses to remain unskilled, his earnings will be $2+r$. When an agent invests in human capital, he will earn

$$
\left(1-e_{i t}^{\prime}\right)(1+r)+w_{t}\left(E_{t-1}+h_{i, t-1}\right)^{\alpha}\left(e_{i t}^{\prime}\right)^{1-\alpha},
$$

where $e_{i t}^{\prime}$ solves

$$
\max _{0 \leq e_{i t} \leq 1}\left(1-e_{i t}\right)(1+r)+w_{t}\left(E_{t-1}+h_{i, t-1}\right)^{\alpha} e_{i t}^{1-\alpha} .
$$

The solution to (9) must satisfy

$$
e_{i t}^{\prime}=\min \left\{1,\left[\frac{(1-\alpha) w_{t}}{1+r}\right]^{1 / \alpha}\left(E_{t-1}+h_{i, t-1}\right)\right\},
$$

which implies, using (4), that human capital is given by 


$$
h_{i t}^{\prime} \equiv \min \left\{\left(E_{t-1}+h_{i, t-1}\right)^{\alpha},\left[\frac{(1-\alpha) w_{t}}{1+r}\right]^{(1-\alpha) / \alpha}\left(E_{t-1}+h_{i, t-1}\right)\right\} .
$$

In this case pre-tax income is

$$
I_{i t}^{\prime} \equiv\left(1-e_{i t}^{\prime}\right)(1+r)+w_{t} h_{i t}^{\prime} .
$$

Therefore, the optimal choice for individual $i$ of generation $t$ is to set

$$
e_{i t}^{*} \equiv\left\{\begin{array}{cc}
0 & \text { if } I_{i t}^{\prime}<2+r \\
e_{i t}^{\prime} & \text { if } I_{i t}^{\prime} \geq 2+r
\end{array}\right.
$$

and

$$
h_{i t}^{*} \equiv\left\{\begin{array}{cl}
0 & \text { if } I_{i t}^{\prime}<2+r \\
\left(E_{t-1}+h_{i, t-1}\right)^{\alpha}\left(e_{i t}^{\prime}\right)^{1-\alpha} & \text { if } I_{i t}^{\prime} \geq 2+r
\end{array}\right.
$$

Since $I_{i t}^{\prime}$ is strictly increasing in $h_{i, t-1}$ we can define a critical value of parental human capital that will determine whether or not an agent will invest in human capital,

$$
h^{c}\left(w_{t}, E_{t-1}\right) \equiv \min \left\{h: I_{i t}^{\prime}\left(w_{t}, E_{t-1}, h\right) \geq 2+r \quad \text { for any } i\right\} .
$$

Inspection of (15) reveals three key components. First, there is a productivity effect. If, when they are adults, wages will not be high enough in the modern sector, agents will not make the sacrifices necessary to enter this sector. This situation can arise if productivity in the modern sector is very low in period $t$, i.e., if $A_{t}$ is small, or if the relative price of modern goods is low, as (3) reveals. Second, there is a parental effect. If a child's parents are very poorly educated, the child will tend not to become skilled even if modern sector productivity is be quite high. Thus, a low level of human capital in the society will discourage much of the younger generation from investing in its own human capital. Third, there is an education system effect. If the quality of the education sector is poor, i.e., $E_{t-1}$ is low, young people will tend not to invest time acquiring human capital because they lack an effective instrument to support their investments.

\subsection{Productivity Growth and Educational Restructuring and Its Financing}

Close involvement in the world economic system leads to the absorption and adaptation of new technologies. This causes Russian productivity to rise toward the world level, denoted $A^{*}$. The rate of endogenous technological and institutional change should depend on the average human capital stock, $m_{t} \equiv \sum_{i=1}^{N}$ $h_{i t} / N$, and its degree of backwardness, $A^{*}-A_{t}$. Accordingly, we posit the productivity growth equation 


$$
A_{t}=A_{t-1}+k\left(m_{t-1}\right)\left(A^{*}-A_{t-1}\right),
$$

where $0<k<1$.

For simplicity, assume that educational restructuring is a one-shot process that is carried out at any time $t$ or deferred indefinitely. Restructuring raises educational quality immediately and permanently from $\underline{E}$ to $\bar{E}$, where $0<\underline{E}<\bar{E}$. If education is restructured in period $s, E_{t}=\underline{E}$ for $t<s$ and $E_{t}=\bar{E}$ for $t \geq s$. Let $I_{i t}^{s}$ denote the pre-tax income of individual $i$ of generation $t$ when the education system is restructured in period $s .{ }^{10}$ The baseline case under which restructuring never takes place is $s=\infty$. Define $\Psi_{t}^{s} \equiv \sum_{i=1}^{N}\left(I_{i t}^{s}-I_{i t}^{\infty}\right)$. Here, $\Psi_{t}^{s}$ is generation $t$ 's total surplus pre-tax income due to restructuring in period $s$ compared to that due to never restructuring.

The following lemma shows that pre-tax income is monotonically decreasing in the restructuring time and is strictly decreasing for educated individuals. For intuition, consider the following thought experiment. Imagine that there are two economies that are identical in all respects except that the first experiences educational restructuring earlier than the second. In the first economy, all educated individuals invest more in human capital, and thus acquire more of it, than do their counterparts in the second economy. Therefore, even though both economies have the same wage rate per unit of human capital, pre-tax incomes are higher in the first economy. Since average human capital is now higher in the first economy than in the second, productivity, and hence the wage rate, grows faster in the first economy. So the second generation in the first economy will enjoy higher wages, will have more parental human capital, and will have a better education system than its counterpart in the second economy. Therefore, this generation will invest more time in human capital formation, acquire more human capital, and earn more income than the second generation in the second economy. This process repeats itself indefinitely. ${ }^{11}$

LeMma 1. (Restructuring generates more pre-tax income.) $I_{i t}^{s}>I_{i t}^{\sigma}, \forall i$ such that $e_{i t}^{s}>0, \sigma>s, t>s$, and $I_{i t}^{s}=I_{i t}^{\sigma}, \forall i$ such that $e_{i t}^{s}=0, \sigma>s, t$.

Proof. Fix $\sigma>s$ and suppose that $e_{i t}^{s}>0$. First consider $t=s+1$. By equation (11), $h_{i t}^{s}>h_{i t}^{\sigma}$, which implies, using Eq. (12), the desired result for $t=$ $s+1$. Straightforward proof by induction, using (4), (11), and (16), shows that $h_{i t}^{s}>h_{i t}^{\sigma}$ and $w_{i t}^{s}>w_{i t}^{\sigma} \forall i$ and $t>s$, which, using (12), yields our conclusion. Finally, suppose $e_{i t}^{s}=0$, which implies $e_{i t}^{\sigma}=0$. The result then follows from Eq. (6).

Lemma 1 might suggest to some readers that it is always optimal to restructure the education system as early as possible. However, we cannot draw this

${ }^{10}$ We will attach a superscript $s$ consistently to all variables to denote their value given that restructuring has occurred in period $s$.

${ }^{11}$ Many proofs are relegated to the Appendix. 
conclusion because the proposition does not take restructuring costs (defined below) into account. To show that restructuring helps a generation requires proving that the surplus it generates is sufficient to cover its cost. On the other hand, Lemma 1 does indicate that any generation having a restructured education system to work with at a fixed cost would prefer that restructuring take place as early as possible.

We assume that educational restructuring requires Russia to borrow a fixed sum, $C$. If education is restructured at time $s$, repayment begins with the adults of generation $s+1$, i.e., the first generation that is able to take advantage of the improved educational opportunities. For simplicity, we assume that the debt is serviced in perpetuity so that each generation after $s+1$ owes $r C$. We refer to the system in which each generation after $s+1$ actually pays $r C$ as normal financing. With the exception of Section 3.5, we assume normal financing. Flexible financing, the alternative to normal financing, is a scheme offered at time 0 , and it allows generation 1 to pay $\Psi_{1}^{0}$ while generation 2 pays $(r C-$ $\left.\Psi_{1}^{0}\right)(1+r)+r C$. This scheme takes advantage of the fact that generation 2 might receive enough surplus from restructuring at time 0 that it will be able to pay not only its own loan service obligations but also the portion of generation 1's obligations with interest that the latter cannot handle out of surplus.

A taxation system is necessary to service the debt. The idea behind the proposed system is as follows. First, the government extracts the entire surplus, $\Psi_{t}^{s}$, from the adult population. It then services the debt and returns the remainder to the adult population with each individual receiving an equal share. ${ }^{12}$ Thus, the income of individual $i$ of generation $t$ when the education system was restructured in period $s$ and normal financing is in place is $Y_{i t}^{s} \equiv I_{i t}^{\infty}+\left(\Psi_{t}^{s}-r C / N\right)$. Under flexible financing, this definition is modified in the obvious way for generations 1 and 2 .

Lemma 2 shows that this taxation and redistribution scheme is nondistortionary so that the taxation system does not affect the path for human capital. ${ }^{13}$ We use Lemma 1 throughout whenever we solve for optimal individual decisions by maximizing pre-tax incomes.

LEMMA 2. The $e_{i t}^{s}$ that maximizes $I_{i t}^{s}$ under either financing scheme is exactly the same as the one that maximizes $Y_{i t}^{s} \forall i, s$, and $t$.

Proof. For $t \leq s, Y_{i t}^{s}=I_{i t}^{s} \forall i$, so the lemma is true. For $t>s, I_{i t}^{\infty}$ does not depend on $e_{i t}^{s}$ and $\Psi_{t}^{s}$ is strictly increasing in $I_{i t}^{s}$, so the lemma is true in this case.

${ }^{12}$ Perotti (1996) uses a similar taxation and redistribution system.

${ }^{13}$ Equal distribution of the surplus that remains after debt service is not essential. As long as income after taxes and redistribution is increasing in pre-tax income, the surplus will not distort decision making. 
Define $s^{*} \equiv \min \left\{s \in S: \Psi_{s+1}^{s} \geq r C\right\}$. Note first that $s^{*}$ is well defined, although $s^{*}=\infty$ is possible. Next note that, under normal financing, any generation before $s^{*}+1$ would vote unanimously against educational restructuring while generation $s^{*}+1$ would vote in its favor. Therefore, any reasonable political economy theory would imply that, under normal financing, educational restructuring would occur precisely at time $s *{ }^{14}$ Therefore, we assume this to be the case, except in Section 3.5, where we consider other financing possibilities.

The following equilibrium definition ties together the pieces in Section 2.

Definition. An equilibrium with educational restructuring at time $s$ is a sequence $\left\{e_{i t}, h_{i t}, A_{t}, w_{t}, E_{t}\right\}$ for $i=1, \ldots, N$ and $t=0,1, \ldots$ such that equations (3), (13), (14), and (16) are satisfied with $e_{i t}=e_{i t}^{*}$ from (13), $h_{i t}=h_{i t}^{*}$ from (14), $E_{t}=\underline{E}$ for $t<s$, and $E_{t}=\bar{E}$ for $t \geq s$.

Section 3 contains a discussion of the steady states defined below.

Definition. A steady state is a set $\left\{h_{1}, \ldots, h_{N}, A, E\right\}$ such that if, at an equilibrium, at some time $t$ and for all $i, h_{i t}=h_{i}, A_{t}=A$, and $E_{t}=E$, then $h_{i t^{\prime}}=h_{i}, A_{t^{\prime}}=A$, and $E_{t^{\prime}}=E$ for all $i$ and $t^{\prime}>t$. A steady state is locally stable if there exists a neighborhood of it such that every equilibrium sequence with constant $E$ starting with initial conditions in this neighborhood converges to it. A steady state is globally stable if every equilibrium sequence with constant $E$ converges to it.

\section{GENERAL ANALYSIS OF THE MODEL}

In this section we present a general analysis of the model. We study not only convergence to steady states (Section 3.1.2) but also the transitional dynamics of human capital at both dynastic and aggregate levels (Section 3.1.1). Section 3.2 studies the timing of educational restructuring and shows that unless it occurs very early in the transition process, certain forces will come into play that will delay it significantly. In Section 3.3 we show that $s^{*}$ is an optimal restructuring time, although earlier times can also be optimal. Section 3.4 shows that this optimal time also reduces inequality. Section 3.5 studies policy implications.

\footnotetext{
${ }^{14}$ Restructuring is implemented if and only if no living agent is hurt. Given the normal financing scheme, this restriction is not as extreme as it might seem. Suppose that restructuring occurs at time $s$. Then generation $s$ are adults for whom the decision is irrelevant because they have already received their education and they will not have to service any loan. Generation $s+1$ are children who will be the first generation to both benefit from and pay for restructuring. The financing scheme operates by taxing away all extra income generated by restructuring, paying loan service, and then either returning to the population the remainder (if there is one) in equal shares or levying additional and equal taxes if more money needs to be raised. Thus, either everyone is a winner or everyone is a loser.
} 


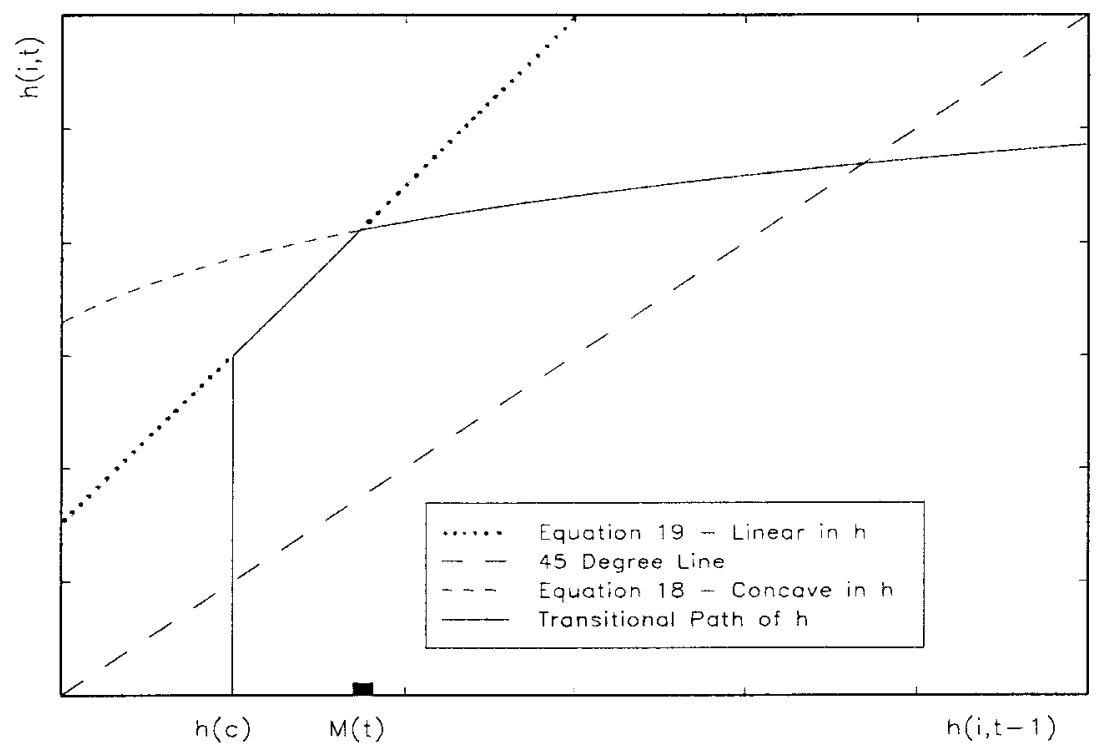

FIG. 1. Transition path for human capital.

\subsection{The Dynamics of Human Capital}

3.1.1. Transitional dynamics. Figure 1 summarizes the information on a single dynasty's transition of human capital between time $t-1$ and time $t$ for a typical parameter set. ${ }^{15}$ Consider Eq. (11) and note that the time individual $i$ of generation $t$ spends acquiring skills will be strictly less than 1 whenever

$$
h_{i, t-1}<\left[\frac{1}{(1-\alpha) w_{t}}\right]^{1 / \alpha}-E_{t-1} \equiv M_{t} .
$$

If the parental human capital of individual $i$ from generation $t$ is above both $M_{t}$ and $h^{c}\left(w_{t}, E_{t-1}\right), e_{i t}=1$ and

$$
h_{i t}=\left(E_{t-1}+h_{i, t-1}\right)^{\alpha} .
$$

If parental skills are below $M_{t}$ and above $h^{c}\left(w_{t}, E_{t-1}\right), 0<e_{i t}<1$ and

$$
h_{i t}=\left[(1-\alpha) w_{t}\right]^{(1-\alpha) / \alpha}\left(E_{t-1}+h_{i, t-1}\right) .
$$

However, if parental human capital is below $h^{c}\left(w_{t}, E_{t-1}\right), h_{i t}=0$.

The primary response of the transition function to technological progress is that $h^{c}$ shifts to the left (Eqs. (3), (12), and (15)), allowing children with less

${ }^{15}$ All of the following figures are drawn with the coefficient on $(E+h)>1$, but this does not have to be the case. 


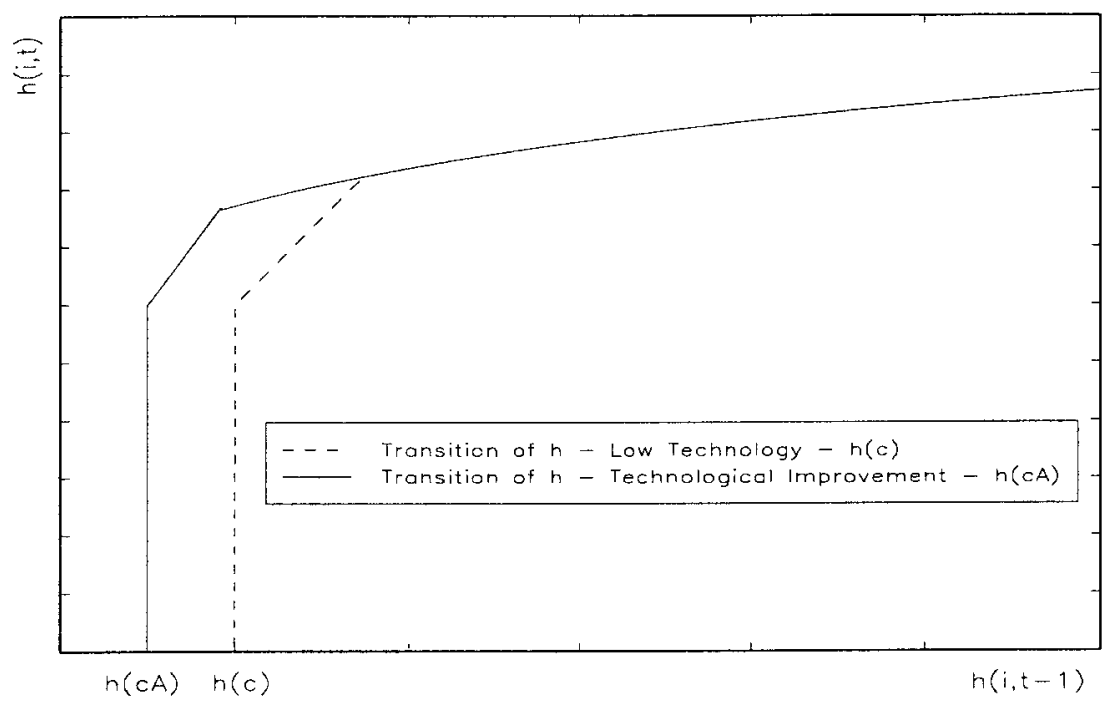

FIG. 2. Human capital transition path under technological improvement.

educated parents to acquire education themselves (Fig. 2). Furthermore, the child devotes more time to education for a given level of parental human capital when $0<e_{i t}<1$ (Eqs. (3) and (10)) and sets $e_{i t}=1$ for a lower level of parental human capital, since $M_{t}$ shifts to the left (Eq. (17)). The underlying cause of these effects is simply that technological progress raises the skilled wage. The transition function responds similarly to educational restructuring as it does to technological progress (see Figs. 2 and 3).

Proposition 1 characterizes the path of human capital for each individual. It shows that, once a child at least matches the educational attainment of his parent, then no subsequent child of this dynasty will ever fail to match the achievement of his parent.

Proposition 1. (Possible human capital paths.) If $h_{i, t+1} \geq h_{i t}$, then $h_{i, \tau+1} \geq h_{i \tau}$ and $I_{i, \tau+1} \geq I_{i \tau} \forall \tau>t$. Moreover, if $h_{i t}>0$ then $I_{i, \tau+1}>I_{i \tau} \forall \tau>t$.

Proof. Suppose $h_{i, t+1} \geq h_{i t}$. By Eqs. (3) and (16) wages cannot decrease in time. Also, recall that the quality of the education system cannot decline. Equation (11) implies directly that $h_{i, \tau+1} \geq h_{i \tau} \forall \tau>t$. This, in turn, using Eq. (10), gives $e_{i, \tau+1} \geq e_{i \tau}, \forall \tau>t$ and, using Eq. (12), gives $I_{i, \tau+1} \geq I_{i \tau} \forall \tau>$ $t$. If $h_{i t}>0$, Eq. (12) gives $I_{i, \tau+1}>I_{i \tau} \forall \tau>t$.

Proposition 1 implies that any dynasty's human capital evolution must follow one of the three qualitative paths shown in Fig. 4. Human capital either increases monotonically from time 0 , decreases monotonically from time 0 , or follows a $\mathrm{U}$-shaped curve. The intuition for the first case relies on the fact that the relative 


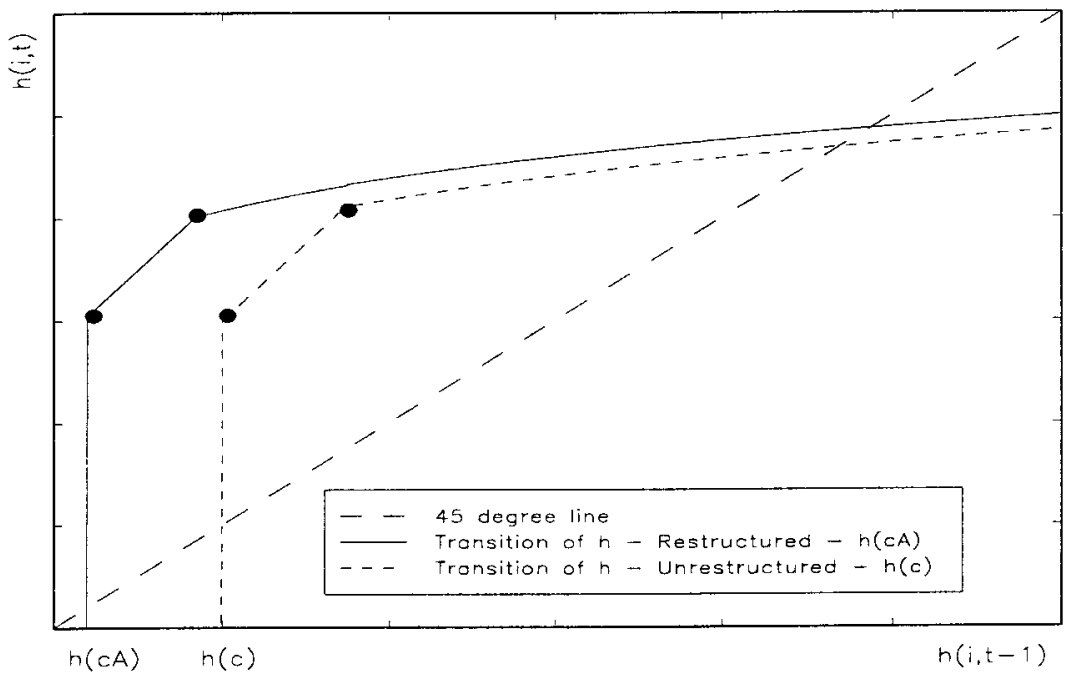

FIG. 3. Human capital transition path under educational restructuring.

wage of skilled labor and the efficiency of the education system are increasing monotonically in time. Therefore, if it was optimal for a child to surpass his parent, it must be optimal for the grandchild, facing an even better human-capital acquisition environment, to surpass the child. The second case can occur if the quality of the education system is poor and wages are low so that a child is not

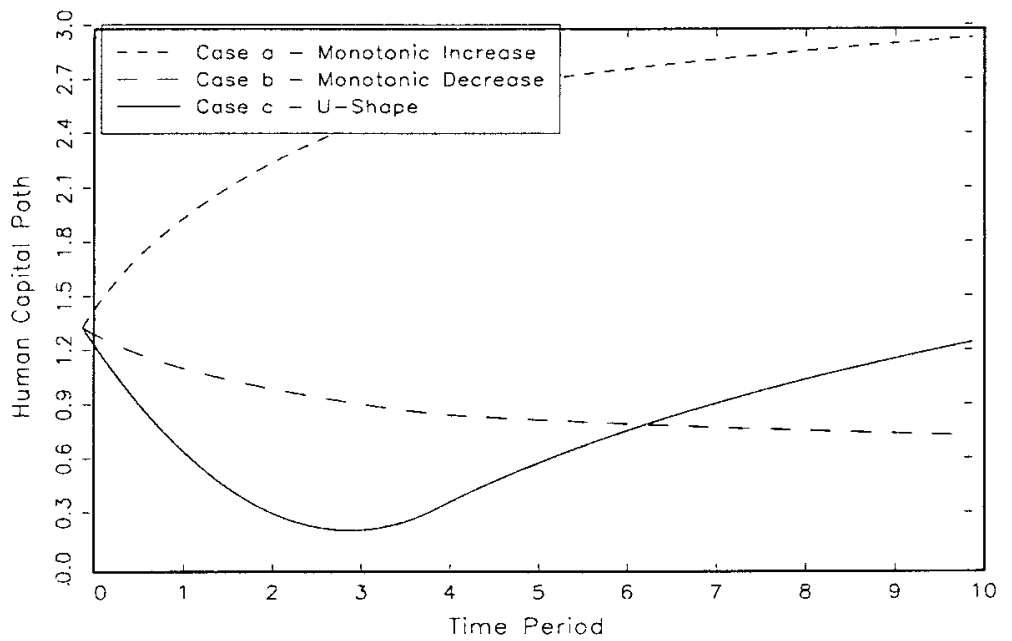

FIG. 4. Qualitative paths for the evolution of human capital. 
willing to reproduce his parent's human capital level. If productivity increases slowly, then a dynasty may continue to run down its human capital. The third case begins with the same conditions, but, due either to a late educational restructuring or a substantial increase in the skilled wage, a child's human capital level might eventually be able to cross over that of his parent's. Once this occurs, the dynamics of the first case take over and human capital for that dynasty never again decreases.

Note that this U-shaped case diverges from the typical results within the new growth theory that generally would allow only for monotonic evolution of a state variable as in the first two cases. This is of more than academic interest because, implicitly, this scenario is the policy of the Russian government. That is, the government is allowing the nation's human capital to deteriorate but certainly does not view itself as leading Russia to a low-human-capital, low-productivity future.

3.1.2. Steady states and convergence. The following proposition shows that, if education is never restructured, then the human capital of each dynasty will converge to either 0 or $\underline{h}$, and if it is restructured, each dynasty will converge to either 0 or $\bar{h}$, where $\underline{h}$ and $\bar{h}$ are defined below. Define $\underline{h}^{1}$ to be the unique solution to $\underline{h}^{1}=\left(\underline{E}+\underline{h}^{1}\right)^{\alpha}$ and $\bar{h}^{1}$ to be the unique solution to $\bar{h}^{1}=\left(\bar{E}+\bar{h}^{1}\right)^{\alpha}$. Define $\underline{h}^{2}$ to be the unique solution to $\left.\underline{h}^{2}=\left[(1-\alpha) p A^{*}\right]^{(1-\alpha) / \alpha)} \underline{E}+\underline{h}^{2}\right)$ if there is one and it is positive. Set $\underline{h}^{2}$ equal to $+\infty$ otherwise. Define $\bar{h}^{2}$ to be the unique solution to $\bar{h}^{2}=\left[(1-\alpha) p A^{*}\right]^{(1-\alpha) / \alpha}\left(\bar{E}+\bar{h}^{2}\right)$ if there is one and it is positive. Set $\underline{h}^{2}$ equal to $+\infty$ otherwise. Next, define $\underline{h} \equiv \min \left(\underline{h}^{1}, \underline{h}^{2}\right)$ and $\bar{h} \equiv \min \left(\bar{h}^{1}\right.$, $\left.\bar{h}^{2}\right)$ and note that $\bar{h}>\underline{h}>0$. Finally, define $\underline{e}$ and $\bar{e}$ by $\underline{h}=(\underline{E}+\underline{h})^{\alpha} \underline{e}^{1-\alpha}$ and $\bar{h}=(\bar{E}+\bar{h})^{\alpha} \bar{e}^{1-\alpha}$.

Proposition 2. (Steady states and convergence.) (a) Suppose that $\underline{h}>h^{c}\left(p A^{*}\right.$, $\underline{E})>0$. Then the set of all locally stable steady states with $E=\underline{E}$ is given by the set of all $\left(h_{1}, \ldots, h_{N}, A^{*}, \underline{E}\right) \neq\left(0, \ldots, 0,0, \ldots, 0, A^{*}, \underline{E}\right)$ such that, for each $i$, either $h_{i}=0$ or $h_{i}=\underline{h}$. None of them are globally stable. All other steady states are of the form $(0, \ldots, 0, A, \underline{E})$, and none of these are stable. (b) Suppose that $\underline{h}>0 \geq h^{c}\left(p\left(A^{*}-\epsilon\right), \underline{E}\right)$ for some $\epsilon>0$. Then $\left(\underline{h}, \ldots, \underline{h}, A^{*}, \underline{E}\right)$ is the unique locally stable steady state with $E=\underline{E}$. States of the form $(0, \ldots, 0, A, \underline{E})$ can be unstable steady states. (c) Suppose that $h^{c}\left(p A^{*}, \underline{E}\right)>\underline{h}$. Then the only steady states are of the form $(0, \ldots, 0, A, \underline{E})$ and none of them are stable. (d) Statements (a), (b), and (c) hold replacing $\underline{h}$ with $\bar{h}$ and $\underline{E}$ with $\bar{E}$.

Proposition 2 leads immediately to the following important corollary.

Corollary 1. (a) In every equilibrium with $s=\infty$, the human capital of every dynasty converges to either 0 or $\underline{h}$. (b) In every equilibrium with finite $s$, the human capital of every dynasty converges to either 0 or $\bar{h}$.

The next proposition shows how the steady state that the economy reaches depends on the timing of educational restructuring. 
Propostion 3. (Comparative steady states.) Suppose that $h^{c}\left(p A^{*}, \bar{E}\right)>0 .($ a) If at any time the human capital of a dynasty falls below $h^{c}\left(p A_{t}, E_{t}\right)$, the human capital of that dynasty vanishes forever. (b) The number of dynasties whose human capital level converges to 0 is decreasing in s.

Proof of Proposition 3. (a) The value of $h^{c}$ can never become lower than that of $h^{c}\left(p A^{*}, \bar{E}\right)$, so the result is immediate. (b) The set of dynasties that end up with zero human capital in the long run is the union of the sets of agents that fall below $h^{c}$ in individual periods. Delaying restructuring results in a permanent downward shift in $h^{c}$ which cannot decrease the set agents that will drop to zero.

The idea is that, once a dynasty fails to meet the critical level of human capital, the education of that dynasty is permanently extinguished because the critical level of human capital will always be greater than 0 in the future. Delaying restructuring from time $s$ to time $\sigma>s$ raises the value of $h^{c}$ during this interval and increases the set of human capital levels that would be destroyed between $s$ and $\sigma$. Thus, any delay in public investment in education would forego some currently available growth potential of the economy.

\subsection{The Timing of Restructuring}

The following proposition casts doubt on the common view that Russian educational restructuring should be a low priority early in the transition process. Holders of this belief, including the present Russian government, invariably also believe that in the not-too-distant future educational restructuring should become a high priority. However, our result suggests that restructuring has a now or much later character, in the sense that if it not implemented early in the process restructuring is not likely to be optimal until much later in the transition process. There is a straightforward intuition for this result. If restructuring is not implemented in period zero, the present generation of young people will invest lightly in education. This will diminish their ability to facilitate their children's human capital development and retard the rate of the economy's productivity growth, further eroding their children's incentive to invest in education. Hence, an educational restructuring initiative in period 1 does not yield enough surplus to allow these children to pay for its cost. Therefore, if restructuring is not implemented in period 0 , it is delayed for at least another generation.

Let $F_{1}$ denote the number of individuals of generation one who will choose to invest zero units of time in acquiring human capital at time 0 if the education system is not restructured at time 0. $F_{1}$ includes all people for whom $h_{i 0}<$ $h^{c}\left(w_{0}, \underline{E}\right)$. 
Proposition 4. (Restructuring: now or much later.) Suppose there exists $i$ such that $h_{i 0} \geq \bar{E}-\underline{E}$. Then if $F_{1}$ is sufficiently close to $N$, it is the case that $s^{*} \neq 0 \Rightarrow$ $s^{*} \neq 1$.

The first condition in the proposition means that the difference for some child of having a highly educated parent versus having a very poorly educated parent is at least as important to his development as is the difference between having a reformed education system versus having an unreformed system. The condition on $F_{1}$ is far from necessary for the result; in the proof, we were forced to make several very pessimistic approximations. Note that as we decrease the rate of growth of productivity in the absence of restructuring, the result will obtain for smaller and smaller values of $F_{1}$.

At the end of Section 2.5, we made the assumption, based on a unanimityvoting rule, that educational reform would occur at time $s^{*}$. Therefore, Proposition 4 can be interpreted as a statement about when reform will actually be implemented. The proposition takes no position on the relative likelihoods of $s^{*}$ $=2,3, \ldots$. However, it does show that $s^{*}=1$ is unlikely. In other words, if restructuring is not conducted right away, it is likely to be delayed at least two generations and possibly longer.

\subsection{The Optimality of $s^{*}$ and Its Egalitarian Properties}

Proposition 5 states that restructuring education at time $s^{*}$, i.e., the first period that reform would be accepted by the political process, guarantees Pareto optimality while it simultaneously Pareto dominates all later times. This means that, while times earlier that $s^{*}$ may also be Pareto optimal, no later time can satisfy this criterion.

Proposition 5. ( $s^{*}$ is an optimal restructuring time.) If $\underline{e} \leq h_{i 0} \leq \bar{e} \forall i$ and $h^{c}\left(w_{0}, \underline{E}\right)<0, s^{*}$ is Pareto optimal and Pareto dominates any $s>s^{*}$.

The conditions imply that the human capital of each dynasty will be nonincreasing in time without restructuring and nondecreasing in time with restructuring. This is a reasonable condition since human capital has been deteriorating in Russia without educational restructuring, and on the other hand, it is difficult to imagine implementing a major educational reform that would not induce individuals to match at least their parents' achievements.

Proof of Proposition 5. By definition of $s^{*}$, restructuring at any time $s<s^{*}$ is harmful to every member of generation $s+1$. It is sufficient to show that $s^{*}$ Pareto dominates any $s>s^{*}$. First, note that the statement is trivially true if $s^{*}$ $=\infty$. Suppose $s^{*}<\infty$ and fix $s>s^{*}$. $Y_{i t}^{s^{*}}=Y_{i t}^{s} \forall t \leq s^{*}$, i.e., all generations preceding time $s^{*}$ are unaffected by whether reform occurs at time $s$ or at time $s^{*}$. Now consider generation $t=s^{*}+1$. Again, by the definition of $s^{*}, Y_{i, s^{*+1}}^{s^{*}}$ $=I_{i, s^{*+1}}^{\infty}+\left(\Psi_{s^{*}+1}^{s^{*}}-r C / N\right) \geq Y_{i, s^{*}+1}^{s}=I_{i, s^{*}+1}^{\infty}$; i.e., after taxes and transfers the 
income of generation $s^{*}+1$ when it benefits from and pays for restructuring is not lower than it would have been without restructuring. Now consider any generation $t>s^{*}+1$. From Lemma 1, any generation that comes after restructuring will want the restructuring to have occurred as early as possible. Therefore, generation $t$ prefers $s^{*}$ to any later time before $t-1$. The only possible problem is that generation $t$ might prefer restructuring to come after time $t-1$ so that it does not have to pay $r C$. In this case $s^{*}$ would not Pareto dominate all later times. However, this cannot occur because, if generation $s^{*}+$ 1 can pay $r C$ out of surplus, all subsequent generations, enjoying higher wages and better educated parents than does generation $s^{*}+1$, will also be able to do so. The Pareto domination argument is complete.

Suppose that $0<s^{*}<\infty$. We know that every generation after $s^{*}$ would prefer an earlier restructuring time, but nevertheless such times are not Pareto optimal because earlier generations would be unwilling to pay their share of the cost under normal financing. Perhaps no other financing scheme would convince any of these generations to change its position. However, we will show in Section 3.4 that there are situations in which the introduction of flexible financing together with an earlier restructuring time than $s^{*}$ can generate a Pareto improvement over $s^{*}$. In these cases, times of $s<s^{*}$ fail for purely financial reasons.

Our next proposition shows that restructuring education at time $s^{*}$ is an egalitarian policy.

Proposition 6. (Restructuring is egalitarian.) Suppose that the conditions of Proposition 5 hold. Then the economy under s* has a lower Gini coefficient for every time after $s^{*}$ than the economy would have for any $s>s^{*}$.

\subsection{Policy Analysis ${ }^{16}$}

The simple political economy framework of Section 2.5 suggests that $s^{*}$ is the restructuring time actually chosen. Proposition 5 indicates that $s^{*}$ is efficient, and Proposition 6 proves that $s^{*}$ is egalitarian. Hence, one might conclude that there is no reason for concern about human capital, growth, and inequality in Russia. However, such an inference would be unwarranted. In particular, suppose $s^{*}=$ 2 , i.e., that generation 1 cannot service the restructuring loan out of surplus. ${ }^{17}$ For several reasons, we cannot endorse the conclusion that restructuring at time 2 is necessarily the best possible policy decision.

${ }^{16}$ Overland and Spagat (1996) consider the policy implications in more detail.

${ }^{17}$ Recall that, by Proposition 3, $s^{*}=1$ is unlikely. This implies that policymakers should not fool themselves into believing that, by not restructuring at time 0 , they are merely postponing restructuring until time 1. 
First, we have shown that $s^{*}$ is Pareto optimal and that it Pareto dominates all later restructuring times. However, time 2 does not Pareto dominate time 0. In fact, by Lemma 1 we know that all generations after and including generation 3 prefer time 0 to time 2. Moreover, it is quite possible that generation 2 prefers time 0 and that generation 1 is close to being on a margin of indifference. In this plausible case, delaying restructuring would give a small advantage to generation 1 while punishing all future generations, perhaps severely. Therefore, while $s^{*}$ is a Pareto optimal choice, it might be undesirable from a broader welfare point of view.

Second, the next proposition shows that expanding the range of financing mechanisms can actually make time 0 Pareto superior to time 2.

Proposition 7. (Flexible financing argues for early restructuring.) Suppose $s^{*}$ $=2$. Restructuring at time 0 using the flexible financing scheme creates a Pareto improvement over restructuring at time 2 under the standard financing scheme if and only if $r C(1+r)+r C \leq \Psi_{1}^{0}(1+r)+\Psi_{2}^{0}$.

Proof of Proposition 7. Moving restructuring from time 2 to time 0 does not hurt generations 1 and 2 by the definition of flexible financing and the assumption $r C(1+r)+r C \leq \Psi_{1}^{0}(1+r)+\Psi_{2}^{0}$. Proposition 4 shows that all subsequent generations gain pre-tax income from this move while at the same time it does not affect any other generation's tax obligations.

One interpretation of Proposition 7 is that an overly precipitous move toward full cost recovery of an educational restructuring can be counterproductive. Generation 1 might reject a proposal to restructure education if they would have to pay their full share of the cost, $r C$. However, if a loan is offered on sufficiently soft terms to this generation, they will accept the arrangement and many members will alter their behavior by investing more of their own time in human capital acquisition. Generation 2, now endowed with higher quality parents as a result of the early reform, will happily make up for the initial softness of the loan. Thus, the availability of temporarily soft financing can have a substantial impact on Russian growth. ${ }^{18}$

\section{CONCLUSION}

The human capital that already exists in Russia is a precious commodity that is currently in a precarious position. During the long transition to a market economy and without solid supporting infrastructure, the private returns to education, especially to a largely unreconstructed Russian education, are likely to

\footnotetext{
${ }^{18}$ Other financing schemes can also help. For example, one that simply adds generation 1's unpaid bill to the debt that is serviced in perpetuity can create an even wider scope for Pareto improvement by moving restructuring up from time 2 to time 0 .
} 
be low. This will cause many young people with the potential to become skilled workers to not bother to invest in themselves. While this internal brain drain could give a temporary boost to economic output, it would seriously undermine long-run economic potential. Fortunately Russia has options that are not available in most developing countries. In particular, the human capital base is sufficiently solid that it can be rescued from excessive deterioration through an early restructuring of its educational system. In principle, such policies could be followed in poorer countries that do not meet the prerequisite of possessing a substantial human capital stock. However, in these countries, the stakes in educational reform are much lower because the unmobilized reserves of human potential that are being stifled by inefficient education are not nearly as large as they are in Russia.

Russia, on the other hand, is in a position to lay the foundations for future prosperity in a relatively costless manner with the help of the international community. Loans directed at restructuring the education system should pay off handsomely in the long run. Money can be directed fruitfully to all levels of the education and research infrastructure. Presently, thousands of teachers and researchers in Russia are giving up their jobs or emigrating because they cannot earn even a living wage in their fields of specialty. This state of affairs creates problems not just for the present; it imperils the whole future development of the country. If a significant portion of the human knowledge present in sectors like health, education, and research is allowed to perish, it will become prohibitively costly to build it up again from scratch.

There has already been some interest from the West in the narrow issue of aiding research institutions in Russia. Some government aid has been directed at preventing military scientists from working for enemies of the West such as North Korea and Iraq. From the perspective of this paper, the efforts of the Hungarian-American entrepreneur George Soros, who has funded a variety of projects to develop Russia's human capital stock, are laudable. It is clear, however, that Western military programs and the efforts of philanthropists will not be sufficient for the task at hand. Private loans would be useful, and far-sighted lenders with a large risk tolerance might be interested in projects that will develop the long-run potential of Russia. However, it is unlikely that many of them will have the patience to wait the requisite period of time. This is precisely where institutions like the World Bank and the European Bank for Reconstruction and Development can fill a crucial niche that is not easily addressed by the private sector or government aid programs. These are the organizations that have the resources and should have the perspective to carry out such a program. Of course, the Russian government must be cooperative and willing to implement a comprehensive educational restructuring plan. In doing so, it would be laying crucial groundwork for the future prosperity of the entire region. 


\section{APPENDIX: PROOFS OF SOME OF THE PROPOSITIONS}

Proposition 2. (Steady states and convergence.) (a) Suppose that $\underline{h}>h^{c}\left(p A^{*}\right.$, $\underline{E})>0$. Then the set of all locally stable steady states with $E=\underline{E}$ is given by the set of all $\left(h_{1}, \ldots, h_{N}, A^{*}, \underline{E}\right) \neq\left(0, \ldots, 0,0, \ldots, 0, A^{*}, \underline{E}\right)$ such that, for each $i$, either $h_{i}=0$ or $h_{i}=\underline{h}$. None of them are globally stable. All other steady states are of the form $(0, \ldots, 0, A, \underline{E})$, and none of these are stable. (b) Suppose that $\underline{h}>0 \geq$ $h^{c}\left(p\left(A^{*}-\epsilon\right), \underline{E}\right)$ for some $\epsilon>0$. Then $\left(\underline{h}, \ldots, \underline{h}, A^{*}, \underline{E}\right)$ is the unique locally stable steady state with $E=\underline{E}$. States of the form $(0, \ldots, 0, A, \underline{E})$ can be unstable steady states. (c) Suppose that $h^{c}\left(p A^{*}, \underline{E}\right)>\underline{h}$. Then the only steady states are of the form $(0, \ldots, 0, A, \underline{E})$, and none of them are stable. (d) Statements $(a),(b)$, and (c) hold replacing $\underline{h}$ with $\bar{h}$ and $\underline{E}$ with $\bar{E}$.

Proof of Proposition 2. First, note that, unless average human capital converges very fast to $0, w_{t} \rightarrow p A^{*}$ so that, except in this extreme case, the dynamic system given in Section 3.1 can be approximated arbitrarily well for large enough $t$ by replacing (17), (18), and (19) with

$$
\begin{aligned}
h_{i, t-1} & <\left[(1-\alpha) p A^{*}\right]^{-1 / \alpha}-\underline{E} \equiv \underline{M} \\
h_{i t} & =\left(\underline{E}+h_{i, t-1}\right)^{\alpha}, \quad \text { and } \\
h_{i t} & =\left[(1-\alpha) p A^{*}\right]^{(1-\alpha) / \alpha}\left(\underline{E}+h_{i, t-1}\right) .
\end{aligned}
$$

We now prove that $\underline{h}$ exists, is unique, and is strictly greater than 0 . First consider (A2). Since $\underline{E}>0$, we know that $h_{i t}>0$ when $h_{i, i-1}=0$. Moreover, $\partial h_{i t} / \partial h_{i, t-1}$ is strictly decreasing, $\lim _{h_{i, t-1} \rightarrow \infty}\left(\partial h_{i t} / \partial h_{i, t-1}\right)=0$, and (A2) is continuous so the graph of (A2) must cross the $45^{\circ}$ line exactly once; i.e., there is a unique $\underline{h}^{1}>$ 0 that is a steady-state solution of (A2). Now consider (A3), which is a straight line such that $h_{i t}>0$ when $h_{i, i-1}=0$. (A3) must cross the $45^{\circ}$ line either never, in the knife-edge case, or once, and then it can be in either the first or the third quadrant. Thus, there is also a unique $\underline{h}^{2}>0$. Recall that $h^{2}$ can equal positive infinity. So $\underline{h} \equiv \min \left(\underline{h}^{1}, \underline{h}^{2}\right)>0$ exists and is unique.

(a) The analysis above shows that, for any $i$, if $h_{i t}$ is in a sufficiently small neighborhood of $\underline{h}$ and $A_{t}$ is in a small neighborhood of $A^{*}$, we have $h_{i t}>h_{i, t-1}$ for $h_{i, t-1}<\underline{h}, h_{i t}<h_{i, t-1}$ for $h_{i, t-1}>\underline{h}$, and $h_{i t}=h_{i, t-1}$ for $h_{i, t-1}=\underline{h}$. Children acquire more (less) human capital than their parents do when their parents have less (more) human capital than $\underline{h}$. If at least one agent begins with $h_{i t}$ in a neighborhood of $\underline{h}, A_{t} \rightarrow A^{*}$.

$(0, \ldots, 0, A, \underline{E})$ will always be a steady state because if every dynasty has zero human. capital then technology does not improve and all dynasties will remain below $h^{c}\left(p A^{*}, \underline{E}\right)$. This steady state will not be stable because any perturbation in $A_{t}$ will remain permanently.

Since there are multiple steady states, none of them can be globally stable. 
(b) Following the analysis in part (a), if a single agent has positive human capital in period $t$, the human capital of this dynasty will converge to $\underline{h}$ as long as $A_{t}$ begins sufficiently close to $A^{*}$.

$(0, \ldots, 0, A, \underline{E})$ will be an unstable steady state as long as $h^{c}(p A, \underline{E})>0$.

(c) Again following part (a), any dynasty with nonzero human capital must eventually enter a small neighborhood of $\underline{h}$, at which point it must jump down to zero.

(d) The proof proceeds exactly as in parts (a), (b), and (c) replacing $\underline{h}$ with $\bar{h}$ and $\underline{E}$ with $\bar{E}$.

Proposition 4. (Restructuring: now or much later.) Suppose there exists $i$ such that $h_{i 0} \geq \bar{E}-\underline{E}$. Then if $F_{1}$ is sufficiently close to $N$, it is the case that $s^{*} \neq 0 \Rightarrow s^{*} \neq 1$.

Proof of Proposition 4. Suppose $s^{*} \neq 0$.

First, we show that if the following two conditions hold, then the proposition is true,

(i) $w_{2}^{\infty}<\min \left[\frac{2+r / \bar{E}^{\alpha},(1-\alpha)^{\alpha-1}(1+r)}{(\bar{E})^{\alpha}(1+r-\alpha)^{\alpha}}\right]$ and
(ii) $w_{2}^{\infty}<\min \left[\frac{r C}{\left(N-F_{1}\right)\left(\bar{E}^{\alpha}-\underline{E}^{\alpha}\right)},\left(\frac{r C}{\left(N-F_{1}\right) \alpha(1-\alpha)^{(1-\alpha) / \alpha}(\bar{E}-\underline{E})}\right)^{\alpha}\right]$.

We claim that (i) implies that the offspring of any individual who acquires zero units of human capital in period zero will acquire zero units of human capital in period one, even if the education system is restructured in period one. Invoking Eq. (14), this will be true as long as

$$
0<\min \left[\left(\frac{2+r}{w_{2}^{\infty}}\right)^{1 / \alpha}-\bar{E}, \frac{(1-\alpha)^{(\alpha-1) / \alpha}(1+r)^{1 / \alpha}}{\left(w_{2}^{\infty}\right)^{1 / \alpha}(2+r-\alpha)}-\bar{E}\right],
$$

which is condition (i) with terms rearranged. We conclude that at least a total of $F_{1}$ individuals generate no surplus so that any educational restructuring in period 1 must be financed by the remaining $N-F_{1}$ individuals.

Next, we claim that (ii) implies that $N-F_{1}$ individuals cannot finance an educational restructuring out of surplus. Equation (12) implies the following. First, $0<e_{i 2}^{\infty}<1 \Rightarrow \Psi_{i 2}^{1} \leq\left(w_{2}^{\infty}\right)^{1 / \alpha}\left[\alpha(1-\alpha)^{(1-\alpha) / \alpha}(\bar{E}-\underline{E})\right]$; i.e., any individual who would devote less than full effort to education without restructuring would receive less than $\left(w_{2}^{\infty}\right)^{1 / \alpha} \alpha(1-\alpha)^{(1-\alpha) / \alpha}(\bar{E}-\underline{E})$ units of surplus. Second, $e_{i 2}^{\infty}=1 \Rightarrow \Psi_{i 2}^{1} \leq w_{2}^{\infty}\left(\bar{E}^{\alpha}-\underline{E}^{\alpha}\right)$; i.e., any individual would invest fully in education even without restructuring would receive less than $w_{2}^{\infty}\left(\bar{E}^{\alpha}-\underline{E}^{\alpha}\right)$ units of surplus. Therefore, using (ii), $\Psi_{2}^{1} \leq\left(N-F_{1}\right) \max \left[w_{2}^{\infty}\left(\bar{E}^{\alpha}-\underline{E}^{\alpha}\right)\right.$, $\left.\left(w_{2}^{\infty}\right)^{1 / \alpha}\left[\alpha(1-\alpha)^{(1-\alpha) / \alpha}(\bar{E}-\underline{E})\right]\right]<r C$. So we have shown that (i) and (ii) imply that $s^{*} \neq 1$. 
Now we show that, for $F_{1}$ close enough to $N$, conditions (i) and (ii) obtain. By (14), the child of any parent with human capital less than

$$
0<\min \left[\left(\frac{2+r}{w_{1}}\right)^{1 / \alpha}-\bar{E}, \frac{(1-\alpha)^{(\alpha-1) / \alpha}(1+r)^{1 / \alpha}}{\left(w_{1}\right)^{1 / \alpha}(2+r-\alpha)}-\bar{E}\right]
$$

will acquire zero human capital. The proposition assumes that $\exists i \exists h_{i 0} \geq \bar{E}-$ $\underline{E}$, so we know that, for $F_{1}$ close enough to $N$,

$$
\bar{E}<\min \left[\left(\frac{2+r}{w_{1}}\right)^{1 / \alpha}, \frac{(1-\alpha)^{(\alpha-1) / \alpha}(1+r)^{1 / \alpha}}{\left(w_{1}\right)^{1 / \alpha}(2+r-\alpha)}\right] .
$$

This implies

$$
w_{1}<\min \left[\frac{2+r}{\bar{E}^{\alpha}}, \frac{(1-\alpha)^{\alpha-1}(1+r)}{\bar{E}^{\alpha}(2+r-\alpha)^{\alpha}}\right] \text {. }
$$

Using (16), as $F_{1} \rightarrow N, w_{2}^{\infty} \rightarrow w_{1}$, so condition (i) holds for $F_{1}$ close enough to $N$.

Inspection of (ii) yields immediately that it holds for $F_{1}$ close enough to $N$.

Proposition 6. (Restructuring is egalitarian.) Suppose that the conditions of Proposition 5 hold. Then the economy under $s^{*}$ has a lower Gini coefficient for every time after $s^{*}$ than the economy would have for any $s>s^{*}$.

Proof of Proposition 6. Choose any $s>s^{*}$. By Proposition 5, we have $\Psi_{t}^{s^{*}}$ $\geq \Psi_{t}^{s} \forall t, s>s^{*}$. Define $\Omega_{t}^{s^{*}, s} \equiv\left(\Psi_{t}^{s^{*}}-\Psi_{t}^{s} / N\right) \geq 0$ so that $Y_{i t}^{s^{*}}=Y_{i t}^{s}+\Omega_{t}^{s^{*, s}}$ $\forall i, t, s>s^{*}$; i.e., restructuring education at time $s^{*}$ rather than time $s$ adds a fixed sum $\Omega_{t}^{s^{*, s}}$ to every individual's income.

Suppose that $\Omega_{t}^{s^{*}, s}>0$. Take any individual $i$ with below-average income, i.e., with $Y_{i t}^{s}<\left(\sum_{i=1}^{N} Y_{i t}^{s} / N\right)$. Cross multiplying both sides by $\Omega_{t}^{s^{*, s}}$ and adding $Y_{i t}^{s} \sum_{i=1}^{N}$ $Y_{i t}^{s}$ to both sides, we have $Y_{i t}^{s} \sum_{i=1}^{N} Y_{i t}^{s}+N \Omega_{t}^{s^{*}, s} Y_{i t}^{s}<Y_{i t}^{s} \sum_{i=1}^{N} Y_{i t}^{s}+\Omega_{t}^{s^{*, s}} \sum_{i=1}^{N}$ $Y_{i t}^{s}$. Rearranging terms,

$$
\frac{Y_{i t}^{s}}{\sum_{i=1}^{N} Y_{i t}^{s}}<\frac{Y_{i t}^{s}+\Omega_{t}^{s^{*}, s}}{\sum_{i=1}^{N} Y_{i t}^{s}+N \Omega_{t}^{s^{*}, s}}=\frac{Y_{i t}^{s^{*}}}{\sum_{i=1}^{N} Y_{i t}^{s^{*}}} .
$$

The same string of operations also proves that

$$
Y_{i t}^{s}=\frac{\sum_{i=1}^{N} Y_{i t}^{s}}{N} \Rightarrow \frac{Y_{i t}^{s}}{\sum_{i=1}^{N} Y_{i t}^{s}}=\frac{Y_{i t}^{s^{*}}}{\sum_{i=1}^{N} Y_{i t}^{s^{*}}}
$$

and

$$
Y_{i t}^{s}>\frac{\sum_{i=1}^{N} Y_{i t}^{s}}{N} \Rightarrow \frac{Y_{i t}^{s}}{\sum_{i=1}^{N} Y_{i t}^{s}}>\frac{Y_{i t}^{s^{*}}}{\sum_{i=1}^{N} Y_{i t}^{s^{*}}} .
$$




\section{If $\Omega_{t}^{s^{*}, s}=0$ then we can conclude that}

$$
\frac{Y_{i t}^{s}}{\sum_{i=1}^{N} Y_{i t}^{s}}=\frac{Y_{i t}^{s^{*}}}{\sum_{i=1}^{N} Y_{i t}^{s^{*}}} .
$$

\section{REFERENCES}

Aage, Hans, "Russian Occupational Wages in Transition." Compar. Econ. Stud. 38, 4:35-52, Winter 1996.

Azariadis, Costas, Intertemporal Macroeconomics. Cambridge, UK: Blackwell, 1993.

Alexeev, Michael, and Kaganovich, Michael, "Returns to Human Capital Under Uncertain Reform: Good Guys Finish Last.” J. Econ. Behav. Organ. 37, 1:53-70, Sept. 1998.

Azariadis, Costas, and Drazen, Allan, "Threshold Externalities in Economic Development." Quart. J. Econ. 105, 2:501-526, May 1990.

Balzer, Harley, "Science, Technology and Education in the former U.S.S.R." In Richard Kaufman and John P. Hardt, Eds., The Former Soviet Union in Transition, pp. 889-908. Armonk, NY: M.E. Sharpe, 1993.

Barro, Robert J., "Human Capital and Economic Growth." In Policies for Long-Run Economic Growth. Symposium Series, pp. 199-216, Kansas City: Federal Reserve Bank of Kansas City, 1992.

Barro, Robert, and Sala-i-Martin, Xavier, "Technology Diffusion, Convergence and Growth." $J$. Econ. Growth 2, 1:1-26, Mar. 1997.

Becker, Gary S., Murphy, Kevin, M., and Tamura, Robert, "Human Capital, Fertility, and Economic Growth.” J. Polit. Econ. 98, 5, Part 2: 312-337, Oct. 1990.

Blanchard, Olivier, The Economics of Post-Communist Transition. Oxford, UK: Clarendon, 1997. Boesman, William, "Science and Technology in the Former Soviet Union: Capabilities and Needs." In Richard Kaufman and John P. Hardt, Eds., The Former Soviet Union in Transition, pp. 610-628. Armonk, NY: M.E. Sharpe, 1993.

Brainerd, Elizabeth, "Winners and Losers in Russia's Economic Transition." Amer. Econ. Rev. 88, 5:1094-1116, Dec. 1998.

Dewatripont, Mathias, and Roland, Gérard, "Economic Reform and Dynamic Political Constraints." Rev. Econ. Stud. 59, 4:703-730, Oct. 1992.

Dewatripont, Mathias, and Roland, Gérard, "Transition as a Process of Large-Scale Institutional Change." Econ. Transition 4, 1:1-30, May 1996.

Galor, Oded, and Tsiddon, Daniel, "The Distribution of Human Capital and Economic Growth." $J$. Econ. Growth 2, 1:93-124, Mar. 1997.

Graham, Loren, Science in Russia and the Soviet Union. Cambridge, UK: Cambridge University Press, 1993.

Heyneman, Stephen, "Economics of Education: Disappointments and Potential." Prospects 25, 4:559-583, Dec. 1995.

Jones, Anthony, "The Educational Legacy of the Soviet Period." In Anthony Jones, Ed., Education and Society in the New Russia. Armonk, NY: M.E. Sharpe, 1994.

Katz, Lawrence F., "Human Capital and Economic Growth: Commentary." In Policies for Long-Run Economic Growth. Symposium Series, pp. 217-224, Kansas City: Federal Reserve Bank of Kansas City, 1992.

Kitaev, Igor V., "The Labor Market and Education in the Post-Soviet Era." In Anthony Jones Ed., Education and Society in the New Russia. Armonk, NY: M.E. Sharpe, 1994.

Lazarev, B. C., Pisarskii, P. C., Sel'tser, P. M., and Sobkin, V. C., Rossiiskaia shkola na rybezhe 90-kh: Sotsiologicheskii analiz. Moscow: Center for the Sociology of Education of the Russian Academy of Sciences, 1993. 
Lucas, Robert, E., Jr., "On the Mechanics of Economic Development.” J. Monetary Econ. 22, 1:3-42, July 1988.

Lucas, Robert, E., Jr., "Making a Miracle.” Econometrica 61, 2:251-272, Mar. 1993.

Mankiw, N. Gregory, Romer, David, and Weil, David N., "A Contribution to the Empirics of Economic Growth.” Quart. J. Econ. 107, 2:407-437, May 1992.

Mulligan, Casey B., and Sala-i-Martin, Xavier, "Transitional Dynamics in Two-Sector Models of Endogenous Growth.” Quart. J. Econ. 108, 3:739-773, Aug. 1993.

Nesterova, Daria V., and Sabirianova, Klara Z., "Investment in Human Capital Under Economic Transformation in Russia.” EERC Working Paper 99/04. Moscow, 1999.

Organization for Economic Cooperation and Development, Science, Technology and Innovation Policies: Federation of Russia. Paris: OECD, 1994.

Ogloblin, Konstantin, "Earning Potential of the Russian Labor Force after Four Years of Transition: The Role of Human Capital," unpublished manuscript, Kent State University, 1997.

Overland, Jody, and Spagat, Michael, "Human Capital and Russia's Economic Transformation." Transition 2, 13:12-15, June 1996.

Perotti, Roberto, "Growth, Income Distribution, and Democracy: What the Data Say." J. Econ. Growth 1, 2:149-187, June 1996.

Sobkin, V. C., and Pisarskii, P. C., Sotsiokul'turnyi analiz obrazovatel'noi situatsii v megapolise. Moscow: Russian Ministry of Education, 1992.

Sobkin, V. C., and Pisarskii, P. C., "Professional'nye orientatsii shkol'nikov: krosskul'tunye razlichiia." In V. C. Sobkin, Ed., Sotsiologiia obrazovaniia. Moscow: Center for the Sociology of Education of the Russian Academy of Sciences, 1993a.

Sobkin, V. C., and Pisarskii, P. C., "Tsennostnye orientatsii starsheklassnikov nachala 90-kh: Krosskul'turnoe sopostablenie (Moskva-Amsterdam)." In Tsennoctno-normativnye orientatsii covremennogo ctarsheklassnika. Moscow: Center for the Sociology of Education of the Russian Academy of Sciences, 1993b.

Spagat, Michael, "Human Capital, Instability and Foreign Investment in Transition Economies." Econ. Planning 28, 2-3:185-203, 1995.

World Bank, Russian Economic Reform. Washington, DC: The World Bank, 1992.

World Bank, World Development Report 1994. Washington, DC: The World Bank, 1994.

World Bank, Russia: Education in the Transition. Washington, DC: The World Bank, 1995.

United Nations, United Nations Demographic Yearbook 1993. New York: United Nations, 1995. 